\title{
Biochemical characteristics of lungs in senescence-accelerated mouse (SAM)
}

\author{
S. Teramoto*, Y. Fukuchi*, Y. Uejima**, K. Teramoto*, H. Orimo*
}

\begin{abstract}
Biochemical characteristics of lungs in senescence-accelerated mouse (SAM). S. Teramoto, Y. Fukuchi, Y. Uejima, K. Teramoto, H. Orimo. @ ERS Journals Ltd 1995.

ABSTRACT: This study examined age-related biochemical changes of the lung in an animal model of senile lung, senescence-accelerated mouse (SAM).

Bronchoalveolar lavage (BAL) was performed on two strains of SAM, the senescenceprone strain (SAM P2) and the senescence-resistant strain (SAM R1), as well as on normal ageing C57 black mice (C57BL), aged 1-24 months. Elastase-like and elastase inhibitory activity of BAL fluid (BALF), glutathione (GSH) and oxidized GSH (GSSG) content both of BALF and lung tissue, and oxygen radical generation of free lung cells obtained by BAL were examined in the three strains of mice.

Cell populations did not change throughout the life in SAM strains and C57BL. The elastolytic activity in SAM was greater than in C57BL, but there was no change with age. Both a decreased content of GSH and an increased oxidation of the GSH in BALF were markedly observed with ageing in SAM P2. In the lung tissue, the GSSG/GSH ratio in SAM strains was consistently greater than that in C57BL, suggesting that the GSH redox cycle of the lung may be impaired in SAM strains. The oxygen radical generation by free lung cells increased with age in all three strains, but the increase was earlier and more pronounced in SAM P2 than in the other two strains.

In conclusion, an impaired GSH redox cycle and an increased formation of oxygen radicals are observed in the lungs of SAM with increasing age.

Eur Respir J., 1995, 8, 450-456.
\end{abstract}

\author{
*Dept of Geriatrics, Faculty of Medicine, \\ University of Tokyo, Tokyo, Japan. **Phar- \\ maceutical Discovery Research Labora- \\ tories, Teijin Institute for Bio-Medical \\ Research, Teijin Ltd, Hino, Tokyo, Japan. \\ Correspondence: S. Teramoto \\ Dept of Medicine \\ Division of Pulmonary Diseases \\ University of North Carolina at Chapel Hill \\ CB \#7020 \\ 724 Burnett-Womack Buildings \\ Chapel Hill \\ NC 27599-7020 \\ USA
}

Keywords: Elastase-antielastase balance oxidant-antioxidant balance senescence-accelerated mouse senile lung

Received: May 111994

Accepted after revision October 311994

This study was supported by Smoking Research Foundation of Japan.
The senescence-accelerated mouse (SAM) is a useful animal model for studying ageing and spontaneous senescence [1]. The senescence-prone (SAM P) strains are characterized by shorter life span (mean survival time (MST) 10.1-12.5 months), a more rapid advance in senescence following normal development, compared with the senescence-resistant (SAM R) strains (MST 16.418.9 months) [2]. The SAM P strains also show a variety of age-related disorders, including cataract [3, 4], amyloidosis [5], memory impairment [6], and senile lung [7, 8].

The senile lung is differentiated from emphysema and characterized both by airspace enlargement without alveolar destruction and the loss of elastic recoil $[9,10]$. A senescence-prone strain of SAM, SAM P2, manifests the functional and morphological characteristics of the senile lung with advancing age, but these changes are seen to occur more slowly in the later life of a senescentresistant strain, SAM R1, which exhibits a relatively normal ageing process [7, 8]. Although the function and morphology of the lungs in SAM strains have been well determined [7-9], the mechanism of development of senile lung is not known. Until now, an increased elastase activity over antielastase capacity has been hypothesized to induce airspace enlargement with alveolar wall destruction $[11,12]$. The elastase-antielastase balance is signi- ficantly influenced by neutrophil infiltration and the oxidant-antioxidant balance of the lung [11-14]. However, the biochemical changes of the lung have not been extensively investigated in SAM. This study was conducted to examine the age-related biochemical changes of the lung in SAM prone versus SAM resistance strains, using bronchoalveolar lavage (BAL), and also in comparison with a normal ageing strain, the C57 black mouse (C57BL).

\section{Methods}

Animals

We used 200 male mice, (76 SAM P2, 76 SAM R1, and $48 \mathrm{C} 57 \mathrm{BL}$ ) in the lung experiments. We also investigated another 206 male mice (104 SAM P2 and 102 SAM R1) regarding survival rate after birth and senility with ageing. Several pairs of SAM P2 and SAM R1 (generously provided by $\mathrm{T}$. Takeda, Chest Disease Research Institute, Kyoto University) were bred in the institute for animal research of Tokyo University. The C57BL/6SCrSlc (C57BL) mice were bred and maintained at the Tokyo Metropolitan Institute animal care facilities under specific pathogen free conditions. The mice were maintained in a limited access barrier during 
the study. SAM P2 is a senescent-prone strain, and was compared with SAM R1, a senescent-resistant strain. The SAM strains were compared with C57 BL mice. The mice were fed on a commercial diet (CE-2, Nihon CLEA Inc., Japan) given water ad libitum, and housed in a temperature $\left(18-24^{\circ} \mathrm{C}\right)$ and humidity $(55 \pm 5 \%)$ controlled room under a $12 \mathrm{~h}$ light and dark cycle. Mice with evidence of underlying disease, such as pneumonia, tumours, and cachexia were excluded from this study.

\section{Assessment of survival rate and senility}

All animals were checked for survival twice a week during the experimental period. The survival rate was calculated at each month after birth using 104 SAM P2 and 102 SAM R1. The senility was checked twice a month in the surviving mice. The senility of each mouse was assessed using the scoring system developed by HosoKawa et al. [15]. This scoring system is composed of 11 categories, including reactivity, passivity, glossiness, coarseness, hair loss, skin ulcer, periophthalmic lesions, cataract, corneal ulcer, corneal opacity and lordokyphosis. Each category has five grades, corresponding to the intensity of the ageing changes. The grading scores for each animal were averaged in each litter, and the mean value of each litter's score was calculated both for SAM R1 and SAM P2 strains.

\section{$B A L$ and biochemical analysis}

The bronchoalveolar lavage was performed on 10 animals at 1, 3, 6, 9, 12, 15 and 18 months of age, on six animals at 24 months of age in both SAM strains, and on six animals at $1,3,6,9,12,15,18$ and 24 months of age in C57BL. Whilst under intraperitoneal anaesthesia (pentobarbital sodium, $10 \mathrm{mg}$ per $100 \mathrm{~g}$ body weight), the animals were intubated with a 22 -gauge Teflon catheter (Deseret Medical Inc., USA). The trachea was exposed and ligated tightly using silk thread. One millilitre of Hanks' balanced salt solution (HBSS) without $\mathrm{Ca}^{++}$and $\mathrm{Mg}^{++}$(Life Technology Inc., USA) was gently infused and recovered. The BAL was repeated twice more in the same way. The BAL fluid (BALF) from each animal lung was pooled and measured for recovery rate. The BALF was centrifuged at $1,000 \mathrm{rpm}$ for $10 \mathrm{~min}$ to form cell pellets. The supernatant was decanted for biochemical analysis. The cells were washed twice and suspended in HBSS.

Cell proportion and viability. A portion of each cell suspension was stained with $0.2 \%$ trypan blue (Wako Pure Chemical Industries Ltd, Japan) and total cell counts in each BAL were calculated with a haemacytometer. Differential counts were performed on cytocentrifuged smears with a modified Wright stain (Diff-Quick fixative, Midori Jyuji Ltd, Japan). Cell viability was evaluated by means of trypan blue exclusion.

Contents of total protein and albumin in BALF. Contents of total protein and albumin in BALF were measured by the method of Lowry et al. [16], and by the albumin Btest Wako (Wako Pure Chemical Industries Ltd, Japan), respectively, using mouse albumin (Sigma Chemical Co., USA) as a standard. In each BALF, the ratio of albumin to protein was calculated as an index for the leakage of albumin into the alveolar space.

Elastase-like activity and elastase inhibitory capacity in $B A L F$. Elastase-like activity in BALF was measured by the ability to cleave p-nitroaniline from succinyl-L-alanylL-alanyl-p-nitroanilide (SLAPN) [17]. For the assay of enzyme activity, $100 \mu \mathrm{l}$ of BALF was added to 100 $\mu \mathrm{l}$ of $0.1 \mathrm{M}$ hydroxyethylpiperazine ethanesulphonic acid (HEPES) (Nakarai Chemical Ltd, Japan) buffer ( $\mathrm{pH}$ 7.4) containing $1 \mathrm{M} \mathrm{NaCl}$ (Wako Chemical Pure Industries Ltd, Japan) and $0.1 \%$ polyethylene glycol 6000 (Wako Chemical Pure Industries Ltd, Japan) in a 96 well microtitre plate; followed by the addition of 50 $\mu 1$ of $2.5 \mathrm{mM}$ substrate in dimethylsulphoxide (Wako Chemical Pure Industries Ltd, Japan). The mixture was incubated at $37^{\circ} \mathrm{C}$ for $4 \mathrm{~h}$. Standards of human sputum elastase (Elastin Product Co. Inc., USA) were assayed in parallel. Changes in absorbance at $405 \mathrm{~nm}$ were measured spectrophotometrically by an electroimmunoassay (EIA) reader Model 2550 (Japan Bio-Rad Laboratories).

Elastase inhibitory capacity in the BALF was measured by microassay using human sputum elastase as a test enzyme with SLAPN as a substrate [17]. One hundred microlitres of BALF was added to $100 \mu \mathrm{l}$ of $0.1 \mathrm{M}$ HEPES buffer ( $\mathrm{pH} 7.4$ ) containing $1 \mathrm{M} \mathrm{NaCl}$ and $0.1 \%$ polyethylene glycol 6000 in a 96 well microtitre plate, and incubated with $25 \mu \mathrm{l}$ of $0.25 \mu \mathrm{M}$ human sputum elastase at $37^{\circ} \mathrm{C}$ for $1 \mathrm{~h}$. Twenty five microlitres of 2.5 $\mathrm{mM}$ substrate in dimethylsulphoxide was added and the mixture was incubated at $37^{\circ} \mathrm{C}$ for $2 \mathrm{~h}$. Human alpha $1^{-}$ protease inhibitor (Sigma Chemical Co., USA) was used as standard for elastase inhibitory capacity. Changes in absorbance at $405 \mathrm{~nm}$ were measured spectrophotometrically.

GSH and GSSG of BALF. Each BALF sample was centrifuged at $12,000 \mathrm{rpm}$ for $2 \mathrm{~min}$ at $4^{\circ} \mathrm{C}$. Nine hundred microlitres of the BALF supernatant was added to 100 $\mu \mathrm{l}$ of $25 \%$ sulphosalicylic acid (SSA) (Wako Chemical Pure Industries Ltd, Japan) solution at $0^{\circ} \mathrm{C}$. The GSH of the supernatant was measured using GSH reductase (Sigma Chemical Co., USA) and SSA, according to the methods of OwENS and BELCHER [18]. These assays were performed using an automatic analyser, COBAS FARA (Roche Diagnostica) [19, 20]. By this method, the GSH measured includes both reduced and oxidized forms. The supernatant was also assayed for oxidized GSH (glutathione disulphide, GSSG) content according to the method of GRIFFITH [21]. Two microlitres of 2-vinylpyridine (Wako Chemical Pure Industries Ltd, Japan) was added to $100 \mu 1$ of each BALF supernatant with $25 \%$ SSA solution. The mixture was allowed to stand for $60 \mathrm{~min}$ at room temperature and assayed by COBAS FARA, using authentic GSSG (Sigma Chemical Co., USA) pretreated with 2-vinylpyridine as a standard. 
GSH and GSSG of lung tissue. After BAL, the lungs of the mice were removed, briefly wiped, and weighed using an analytical balance (Sartorius Corp., Tokyo, Japan). The lung tissue was homogenized using a Teflon homogenizer (Wheaton) following mixture with 10 fold $2.5 \%$ SSA solution, and centrifuged at 12,000 rpm for $2 \mathrm{~min}$ at $4^{\circ} \mathrm{C}$. The supernatant was then obtained. Both the GSH and GSSG content of the supernatant were measured as described previously.

Oxygen radical generation by BAL cells. Oxygen radical generation by BAL cells (also referred to as free lung cells) was measured by the lucigenin-dependent chemiluminescence method using a photon counter, Biolumat LB9505 (Berthold, FRG). The oxygen radical generation by free lung cells was determined as the increase of chemiluminescence after stimulation with phorbol-12myristate-13-acetate (PMA) (Sigma Chemical Co.). Free lungs cells, $10^{5}$, harvested from the BAL in each mice were suspended in $900 \mu \mathrm{l}$ of HBSS containing $\mathrm{Ca}^{++}$and $\mathrm{Mg}^{++}$(pH 7.4) (Life Technologies, Inc., USA), and prewarmed for $15 \mathrm{~min}$ at $37^{\circ} \mathrm{C}$ with $50 \mu \mathrm{l}$ of lucigenin (2 $\left.\mathrm{mg} \cdot \mathrm{ml}^{-1}\right)$. Oxygen radical generation was measured for $90 \mathrm{~min}$ at $37^{\circ} \mathrm{C}$ with stimulation of $10 \mu \mathrm{l}$ of PMA $(0.1$ $\mathrm{mg} \cdot \mathrm{ml}^{-1}$ ) or $50 \mu 1$ of opsonized zymosan (OZ). Zymosan A (Sigma Chemical Co.) was prepared and opsonized with fresh human serum. Data were expressed as the peak counts of chemiluminescence for 90 min after stimulation $[22,23]$.

\section{Statistical analysis}

Statistical analysis of differences between each strain of mice group at the same age was performed using Student's t-test. Differences with age in each strain were determined using analysis of variance (ANOVA) coupled with Bonferroni/Dunn test. Values of $p$ less than 0.05 were considered significant.

\section{Results}

\section{Survival rate and age-related changes in senility}

The median survival time in the SAM P2 strain was $11.1 \pm 1.2$ months (mean $\pm \mathrm{SD}$ ). This was significantly shorter than in the SAM R1 strain with survival of $16.1 \pm 1.8$ months $(\mathrm{p}<0.01)$. The senility grading score gradually increased with age in each strain of mice (fig. 1). The increase was most rapid in SAM P2. The total score in both SAM strains was significantly greater than that in C57BL, and the differences between the SAM strains and C57BL increased with age.

\section{Biochemical analysis of the BAL}

In this study, the recovery rate of BALF was over $75 \%$ in all animals, and there were no significant differences in the rates at different ages. Accordingly, we evaluated the cell components and other parameters in BAL in terms of millilitres of BALF.

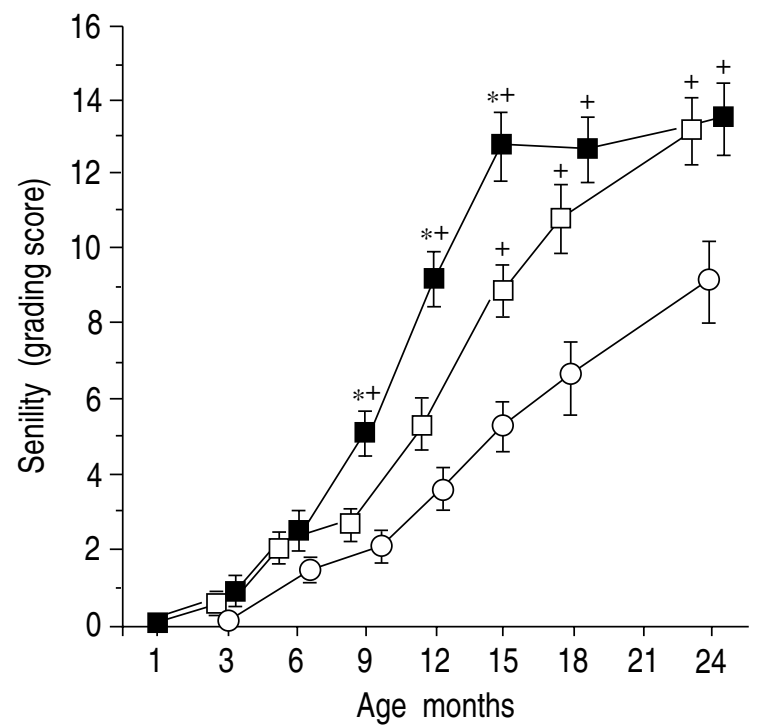

Fig. 1. - Age-related changes in the senility grading score in SAM strains and C57BL mice. - - : SAM R1; —— : SAM P2; $\longrightarrow$ : C57BL. Each value represents the mean \pm SD of 10 mice from 1-18 months of age and the mean \pm SD of six mice at 24 months of age in SAM strains, and the mean \pm SD of six animals of C57BL at different ages. *: $\mathrm{p}<0.05$ compared with the value at 3 months of age in the same strain; $+: \mathrm{p}<0.05$, compared with the value at same age in C57BL. SAM: senescence-accelerated mouse; SAM P2: senescence prone strain; SAM R1: senescence resistant strain; C57BL: normal ageing black mice.

Cell proportion and viability. More than $90 \%$ of the cells obtained were viable in all animals. The total cell count in BALF in both strains of SAM was less than $5 \times 10^{5}$ cells; the percentage of alveolar macrophages was $>90 \%$, polymorphonuclear leucocyte $<1.5 \%$, and lymphocyte $<5 \%$. No significant age-related differences in the number or proportion of BAL cells were seen in any strain.

Contents of total protein and albumin in BALF. There was no difference in the content of albumin at different ages in both strains of SAM and in C57BL. The ratio of albumin to protein in BALF is shown in figure 2 . The albumin/protein ratio was unchanged up to 24 months of age in the three strains of mice.

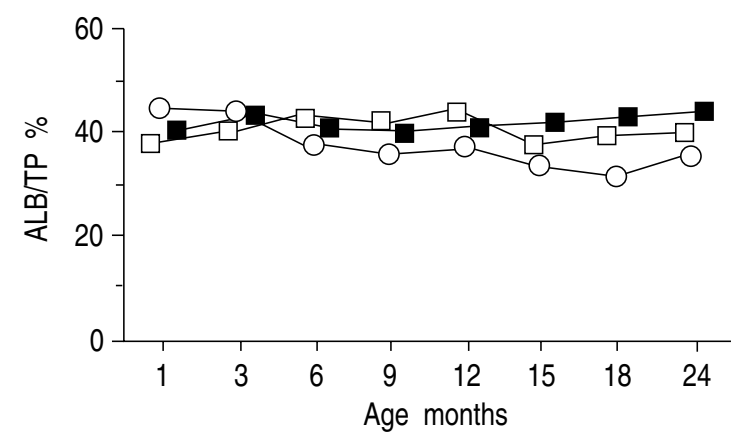

Fig. 2. - Age-related changes in the albumin/total protein (ALB/TP) ratio of bronchoalveolar lavage (BAL) fluid in SAM strains. - $\square$ : SAM R1; ——: SAM P2; ○—: C57BL. Each value represents the mean of 10 mice from $1-18$ months of age and the mean of six mice at 24 months of age in SAM strains, and the mean of six animals of C57BL at different ages. For abbreviations see legend to figure 1. 


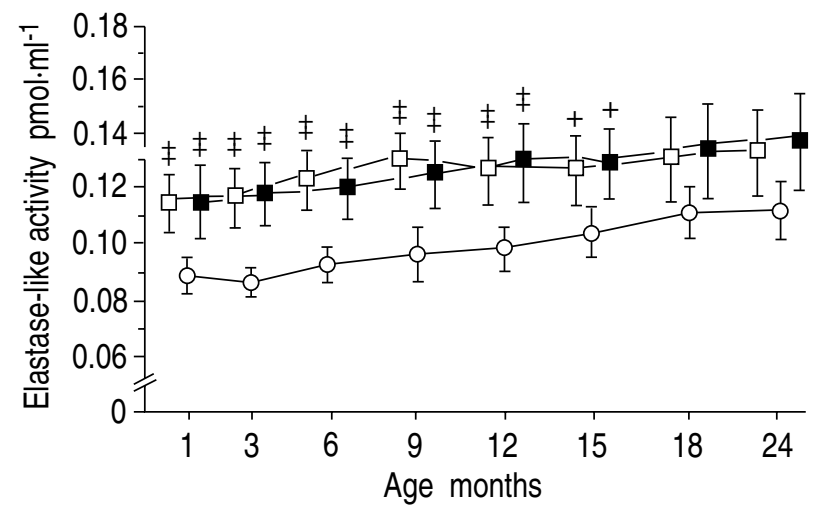

Fig. 3. - Age-related changes in elastase-like activity of bronchoalveolar lavage fluid (BAL). - $\square$ : SAM R1; —— : SAM P2; —o- : C57BL. Each value represents the mean \pm SD of 10 mice from 1-18 months of age and the mean \pm SD of six mice at 24 months of age in SAM strains, and the mean \pm SD of six animals of C57BL at different ages. $+: \mathrm{p}<0.05 ; \ddagger: \mathrm{p}<0.01$, compared with the value at the same age in C57BL. For abbreviations see legend to figure 1.

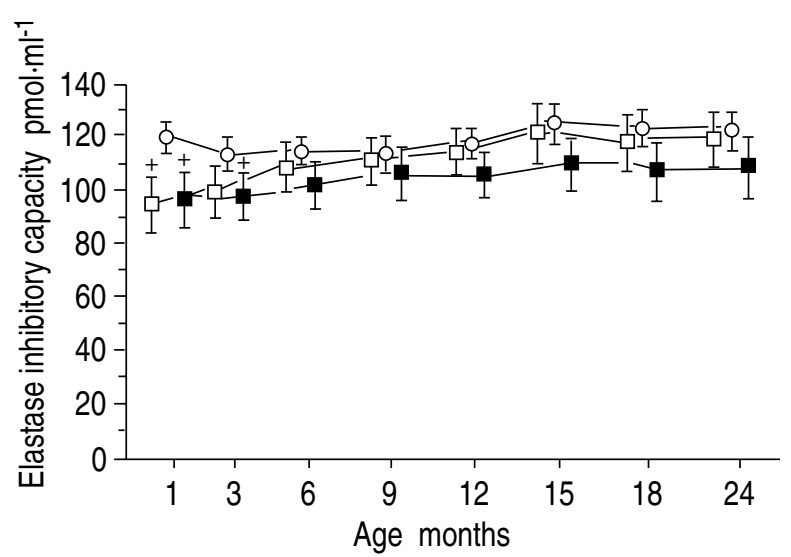

Fig. 4. - Age-related changes in elastase inhibitory capacity in

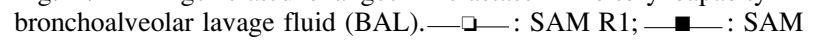
$\mathrm{P} 2 ;-\mathrm{O}-\mathrm{C} 57 \mathrm{BL}$. Each value represents the mean \pm SD of 10 mice from 1-18 months of age and the mean \pm SD of six mice at 24 months of age in SAM strains, and the mean \pm SD of six animals of C57BL at different ages. +: $\mathrm{p}<0.05$, compared with the value at the same age in C57BL. For abbreviations see legend to figure 1.

Elastase-like activity and elastase inhibitory capacity in $B A L F$. The alterations in elastase-like activity and elastase inhibitory capacity in BALF are depicted in figures 3 and 4, respectively. No age-related change was observed either in elastase-like activity or in elastase inhibtory capacity. However, the elastase-like activity in SAM strains was significantly greater than that in C57BL from 1-15 months of age. On the other hand, the elastase inhibitory capacity in SAM strains was smaller than that in C57BL from 1-3 months of age.

GSH and GSSG of BALF. Age-related changes in GSH content in BALF are shown in figure 5. The GSH concentration of BALF in both SAM strains was consistently lower than that in C57BL throughout the life span. In addition, a significant decrease in GSH of BALF was observed with advancing age both in SAM R1 and SAM P2.

The ratio of GSSG to GSH in BALF at different ages is depicted in figure 6 . The GSSG/GSH ratio in SAM

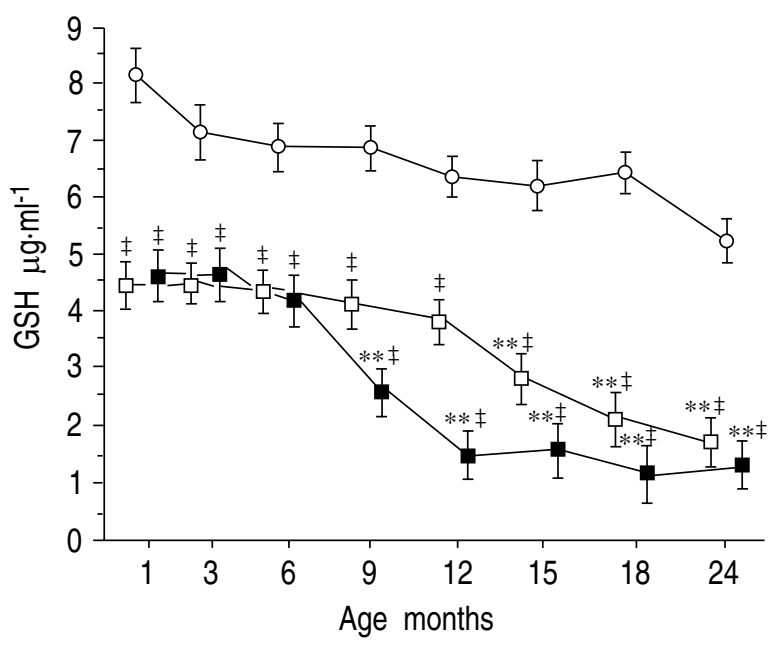

Fig. 5. - Age-related changes in glutathione (GSH) content of bronchoalveolar lavage fluid (BAL).—-: SAM R1; ——: SAM $\mathrm{P} 2 ;-\bigcirc-$ : C57BL. Each value represents the mean \pm SD of 10 mice from 1-18 months of age and the mean \pm SD of six mice at 24 months of age in SAM strains, and the mean \pm SD of six animals of C57BL at different ages. $* *: \mathrm{p}<0.01$, compared with the value at 3 months of age in the same strain; $¥: \mathrm{p}<0.01$, compared with the value at same age in C57BL. For abbreviations see legend to figure 1.

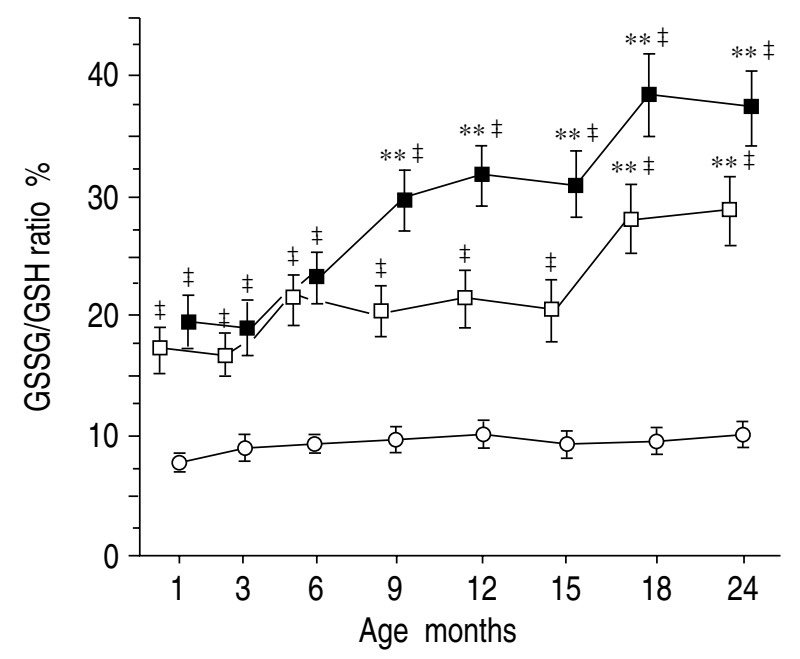

Fig. 6. - Age-related changes in the ratio of oxidized GSH (GSSG) to GSH in bronchoalveolar lavage fluid (BAL). - $\square-$ : SAM R1; $\longrightarrow$ : SAM P2; - - C57BL. Each value represents the mean \pm SD of 10 mice from 1-18 months of age and the mean \pm SD of six mice at 24 months of age in SAM strains, and the mean \pm SD of six animals of C57BL at different ages. **: $\mathrm{p}<0.01$, compared with the value at 3 months of age in the same strain; $\ddagger: p<0.01$, compared with the value at same age in C57BL. For abbreviations see legend to figure 1.

strains was significantly higher than that in C57BL from 1-24 months of age. After 9 months of age, marked differences were observed in the GSSG/GSH ratio between SAM strains and C57BL.

GSH and GSSG of lung tissue. Figures 7 and 8 show the GSH content and the GSSG/GSH ratio of the lung tissue, respectively. Age-related decline of GSH content was seen in SAM strains, but not in C57BL up to 24 months of age. The SAM strains had a relatively 


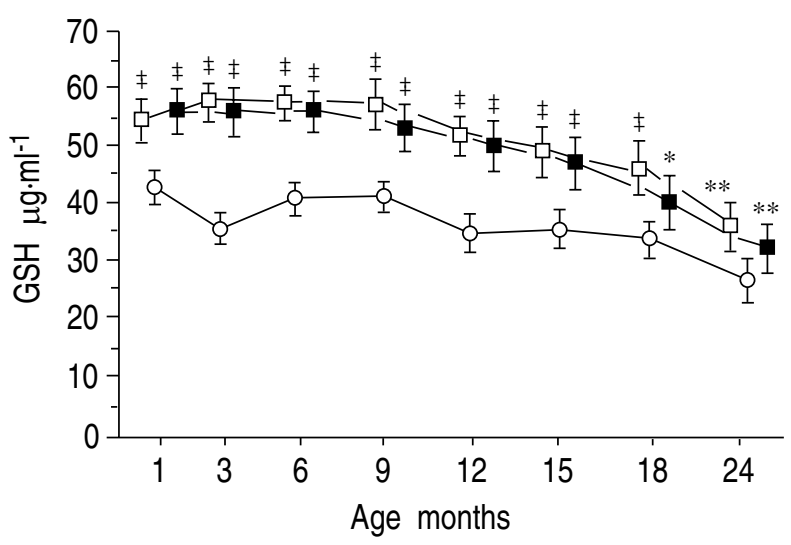

Fig. 7. - Age-related changes in glutathione (GSH) content of lung. $\longrightarrow$ - SAM R1; —-: SAM P2; ——: C57BL. Each value represents the mean \pm SD of 10 mice from 1-18 months of age and the mean \pm SD of six mice at 24 months of age in SAM strains, and the mean \pm SD of six animals of C57BL at different ages. *: $\mathrm{p}<0.05 ; * *$ : $\mathrm{p}<0.01$, compared withe the value at 3 months of age in the same strain; +: $\mathrm{p}<0.05 ; \ddagger: \mathrm{p}<0.01$, compared with the value at same age in C57BL. For abbreviations see legend to figure 1.

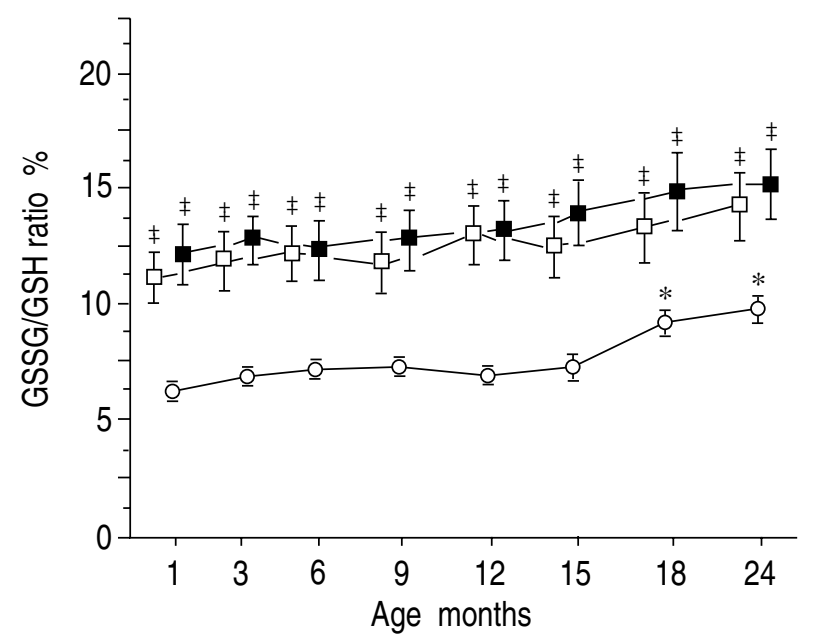

Fig. 8. - Age-related changes in the ratio of oxidized GSH (GSSG) to GSH of lung. $\longrightarrow-$ SAM R1; $\square$ : SAM P2; ——: C57BL. Each value represents the mean \pm sD of 10 mice from 1-18 months of age and the mean \pm SD of six mice at 24 months of age in SAM strains, and the mean \pm SD of six animals of C57BL at different ages. $*: p<0.05$; **: $\mathrm{p}<0.01$, compared with the value at 3 months of age in the same strain; +: $\mathrm{p}<0.05 ; \ddagger: \mathrm{p}<0.01$, compared with the value at same age in C57BL. For abbreviations see legend to figure 1 .

higher GSH concentration compared with C57BL. The GSSG/GSH ratio of the lung in SAM strains did not change with age, but was approximately two times higher than that in C57BL throughout the life.

Oxygen radical generation by BAL cells. Figure 9 shows that oxygen radical generation by free lung cells after stimulation with PMA or OZ significantly increased with age in each strain of mice. This increase occurred earlier and was more pronounced in SAM P2 than in SAM $\mathrm{R} 1$ and C57BL. Already at 9 months of age the difference in oxygen radical generation between SAM P2 and C57BL was significant.
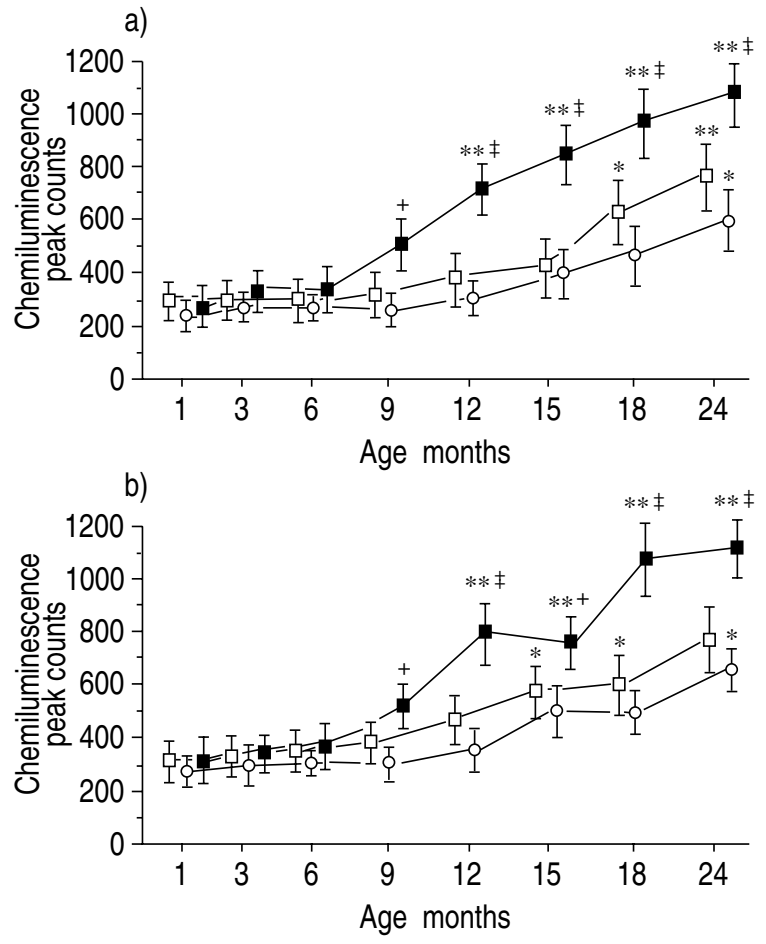

Fig. 9. - Age-related changes in the oxygen radicals generation by free lung cells after stimulation: a) with PMA; or b) OZ. PMA: phorbol myristate acetate; OZ: opsonized zymosan. The oxygen radical generation was presented as peak counts of chemiluminescence. - $\square$ : SAM $\mathrm{R} 1 ;--$ : SAM P2; $\longrightarrow$ : C57BL. Each value represents the mean \pm SD of 10 mice from 1-18 months of age and the mean \pm sD of six mice at 24 months of age in SAM strains, and the mean \pm SD of six animals of C57BL at different ages. *: $\mathrm{p}<0.05 ; * *$ : $\mathrm{p}<0.01$, compared with the value at 3 months of age in the same strain; + : $p<0.05$; $\ddagger$ : $\mathrm{p}<0.01$, compared with the value at same age in C57BL. For abbreviations see legend to figure 1 .

\section{Discussion}

A wide variety of morphological, functional, and biochemical changes have been described in the lungs of humans with ageing [9, 10, 24-29]. These changes may result not only from physiological ageing, but also from pathological changes induced by tobacco smoke, environmental pollution and chronic lung disease. At present, the physiological ageing of the lung without noxious insults has been proposed as a senile lung, which is characterized both by airspace enlargement without alveolar wall destruction and loss of elastic recoil [9, 10]. Because it is difficult to distinguish "true" ageing effect from the cumulative effect of environmental insults in human, an appropriate animal model for the study of the senile lung may be useful [8].

Recently, we demonstrated that a strain of senescenceaccelerated mouse (SAM), SAM P2, exhibited functional and morphological alterations of the senile lung within the time course of ageing, and might be a good model to examine the development of senile lung $[7,8]$. The investigation of differences between SAM and normal ageing mice may offer information regarding the cause and mechanism of development of senile lung. The purpose of the current study was to elucidate the biochemical characteristics of the lung in SAM in comparison with a normal ageing mice, C57BL. 
Age-related changes and strain-related differences in the oxidant-antioxidant and elastase-antielastase balance of distal lung spaces using bronchoalveolar lavage were examined, since the oxidant-antioxidant and elastaseantielastase balance may be related to the morphological changes of the lung [11-14], and these imbalances may result in lung disorders [30-32]. In addition, free radical formation and accumulation of free radical damage may play a role in the ageing processes [33, 34].

The elastase-like activity and the elastase inhibitory capacity did not differ at different ages in any strain of mice. The leakage from serum component as indexed by the ratio of albumin to total protein in BALF did not increase with ageing, indicating that inflammatory changes associated with increased elastase activity do not occur with physiological ageing under ideal conditions. The results may be consistent with rarely seen infiltration of inflammatory cells into alveolar lesions and relatively intact alveolar walls on histological examination [8]. The number and the proportion of lung cells recovered in BALF did not show age-related changes, and the neutrophils harvested from BAL were less than $1.5 \%$ of total cell numbers throughout the life-span in all strains. However, the level of elastase activity of BALF in SAM was slightly higher, and the level of antielastase activity of BALF in SAM was slightly lower, than the levels in C57BL, suggesting a mild elastaseantielastase imbalance in the lung of SAM strains. This small difference between SAM strains and C57BL may contribute little to morphological changes during physiological ageing, but could be of greater influence in the presence of noxious insults, because significant elastase-antielastase imbalance and emphysematous alterations of lung following chronic tobacco smoke inhalation have been reported in SAM $[35,36]$. In this study, the elastase-like activity and antielastase activity were examined using human sputum elastase as a standard. Although the results were consistent and reproducible throughout the study, the species differences in response to human sputum elastase should be considered when comparing the results with other studies [17]. In our experience, results from experiments using human sputum elastase are more sensitive and reproducible than results using porcine pancreatic elastase (data not shown).

Glutathione (GSH) is one of the major antioxidant systems in mammalian species and present in alveolar epithelial lining fluid (ELF) in high concentrations [37]. In the present study, decreased contents of GSH and increased oxidation of GSH both in BALF and lung tissue were observed with ageing in SAM strains and occurred earlier in the SAM P2 strain. The magnitude of these changes in SAM was significantly greater than that in C57BL, indicating that the GSH system is markedly impaired in SAM. However, the GSH concentration of lung tissue in SAM was consistently higher than that in C57BL. The results were contrary to the data showing that GSH content of BALF in SAM was significantly smaller than that in C57BL. Because the GSSG/GSH ratio of lung tissue in SAM was about twofold higher than that in C57BL, a possible explanation is that the cycle of oxidized GSH to the reduced GSH of lung may be impaired in SAM strains, and that then the GSH export from lung to alveolar ELF may be disturbed.

Oxygen radical formation of the distal lung may induce lung damage, and contribute to decreased antielastase activity due to inactivation of methionine residue in alpha $_{1}$-antitrypsin. In SAM strains, there was an increased oxidant generation by free lung cells obtained from BAL with increasing age. The formation of oxygen radicals in SAM P2 was 2-3 fold greater than that in C57BL after either stimulation of phorbol ester or opsonized zymosan. The results indicate that the lung macrophages in SAM may be more strongly activated by the protein kinase $\mathrm{C}$ pathway and/or by complement-associated pathways. Because the increased oxidant production may utilize scavenger systems and could lead to oxidation of $\mathrm{GSH}$, the results may also partly explain the increased GSSG/GSH ratio of BALF and lung tissue in SAM.

Therefore, an impaired GSH system and an increased oxygen radical formation of the lung may be a major characteristics of SAM. In the current study, we did not measure the whole antioxidant capacity of the lung. It is still not known whether the antioxidant activity of the lung is truly decreased with ageing in SAM, because a decreased activity in one component of antioxidants may be compensated for by increased activity of other antioxidants. However, the marked differences in GSH redox cycle between C57BL and SAM may argue in favour of a major role for GSH in lung defence mechanisms, and SAM may provide an interesting model to investigate the relationship between GSH and lung development.

UEJIMA and co-workers [35, 36] reported that the senescence-prone strains in SAM exhibited biochemical and morphological alterations in lungs following chronic tobacco smoke inhalation. After 5 weeks of tobacco exposure, oxidant-antioxidant and elastase-antielastase imbalance were found in SAM P strains along with significant airspace enlargement. The morphological alterations were accompanied by marked infiltration of neutrophils into airspaces, suggesting that the inflammatory cells may generate the oxygen radicals, and could lead to elastase-antielastase imbalance both by an increased production of elastase from neutrophils and an inactivation of antielastase activity. Taken together with the current study, the impairment of the oxidant-antioxidant balance in SAM may not be obvious under natural ageing, but could be markedly exacerbated by noxious insults, such as chronic tobacco smoke, and then might result in alveolar destruction and inflammation, with a marked elastase-antielastase imbalance. Therefore, SAM may also be useful to investigate effects of tobacco smoke and other noxious agents on senile lung from biochemical and morphological aspects.

Acknowledgements: The authors thank T. Takeda (Chest Disease Research Institute, Kyoto University, Japan) for kindly supplying SAM. They also thank Y. Tateno, M. Ito and R. Tabata for their technical help and animal care.

\section{References}

1. Takeda T, Hosokawa M, Takeshita S, et al. A new murine model of accelerated senescence. Mech Ageing Dev 1981; 17: 183-194. 
2. Takeda T, Hosokawa M, Higuchi K. Senescence-accelerated mouse (SAM): a novel murine model of accelerated senescence. J Am Geriatr Soc 1991; 39: 911-919.

3. Hosokawa M, Takeshita S, Higuchi $\mathrm{K}$, et al. Cataract and other ophthalmic lesions in senescence accelerated mouse (SAM): morphology and incidence of senescence associated ophthalmic changes in mice. Exp Eye Res 1984; 38: 105-114.

4. Teramoto S, Fukuchi Y, Uejima Y, Ito H, Orimo H. Age-related changes in GSH content of eyes in mice: a comparison of senescence-accelerated mouse (SAM) and of C57BL/J mouse. Comp Biochem Physiol 1992; 102A: 693-696.

5. Takeshita S, Hosokawa M, et al. Spontaneous ageassociated amyloidosis in senescence-accelerated mouse (SAM). Mech Ageing Dev 1982; 20: 13-23.

6. Flood JF, Morley E. Early onset of age-related impairment of aversive and appetitive learning in the SAM-P/8 mouse. J Gerontol 1992; 47: B52-B59.

7. Teramoto S, Fukuchi Y, Uejima Y, Orimo H. Agerelated changes of the lung in senescence-accelerated mouse (SAM): a novel model of senile lung. Am Rev Respir Dis 1993; 147: A693.

8. Teramoto S, Fukuchi Y, Uejima Y, Teramoto K, Oka T, Orimo H. A novel model of senile lung: senescenceaccelerated mouse (SAM). Am J Respir Crit Care Med 1994; 150: 238-244.

9. Verbeken EK, Cauberghs M, Mertens I, et al. The senile lung: comparison with normal and emphysematous lungs. 1. Structural aspects. Chest 1992; 101: 793-799.

10. Verbeken EK, Cauberghs M, Mertens I, Clement J, Lauweryns JM, Van de Woestijne KP. The senile lung: comparison with normal and emphysematous lungs. 2 . Functional aspects. Chest 1992; 101: 800-809.

11. Gadek JE, Fells GA, Zimerman RL, Rennard SI, Crystal RG. Antielastases of the human alveolar structures: implications for the protease-antiprotease theory of emphysema. J Clin Invest 1981; 68: 889-898.

12. Janoff A. Elastases and emphysema: current assessment of the protease-antiprotease hypothesis. Am Rev Respir Dis 1985; 132: 417-433.

13. Freeman BA, Crapo JD. Biology of disease free radicals and tissue injury. Lab Invest 1982; 47: 412-426.

14. Carp H, Miller F, Hoidal JR, Janoff A. Potential mechanism of emphysema: alpha $a_{1}$-protease inhibitor recovered from lungs of cigarette smokers contains oxidized methionine and has decreased elastase inhibitory capacity. Proc Natl Acad Sci USA 1982; 79: 2041-2045.

15. Hosokawa M, Kasai R, Higuchi K, et al. Grading score system: a method for evaluation of the degree of senescence in senescence-accelerated mouse (SAM). Mech Ageing Dev 1984; 26: 91-102.

16. Lowry OH, Rosenbrough NJ, Farr AL, Randall RJ. Protein measurement with the folin phenol reagent. J Biol Chem 1951; 193: 265-275.

17. Bieth J, Spiess B, Wermuth CG. The synthesis and analytical use of a highly sensitive and convenient substrate of elastase. Biochem Med 1974; 11: 350-357.

18. Owens CWI, Belcher RV. A calorimetric micro-method for the determination of glutathione. Biochem J 1965; 94: 705-711.
19. Teramoto S, Fukuchi Y, Uejima Y, Ito H, Araki A, Orimo $\mathrm{H}$. Influence of age on oxidant-antioxidant balance of distal lung in C57/BL6 mouse and in senescence-accelerated mouse (SAM). Am Rev Respir Dis 1992; 145: A573.

20. Teramoto S, Fukuchi Y, Uejima Y, Teramoto K, Orimo H. Age-related changes in antioxidant screen of distal lung in mice. Lung 1994; 172: 223-230.

21. Griffith OW. Determination of glutathione and glutathione disulfide using glutathione reductase and 2-vinylpyridine. Anal Biochem 1980; 106: 207-212.

22. Teramoto S, Fukuchi Y, Uejima Y, Teramoto K, Orimo $\mathrm{H}$. Influences of chronic tobacco smoke inhalation on aging and oxidant-antioxidant balance in senescenceaccelerated mouse (SAM)-P/2. Exp Gerontol 1993; 28: 87-95.

23. Teramoto S, Fukuchi Y, Chu C-Y, Orimo H. Influences of cisplatin combination chemotherapy on oxygen radical generation of blood in elderly and adult patients with lung cancer. Chemotherapy 1995; 41: (in press).

24. Pump KK. The aged lung. Chest 1971; 60: 571-577.

25. Turner JM, Mead J, Wohl ME. Elasticity of human lungs in relation to age. J Appl Physiol 1968; 25: 664-671.

26. Knudson RJ, Clark DF, Kennedy TC, Knudson DE. Effect of aging alone on mechanical properties of the normal adult human lung. J Appl Physiol 1977; 43: 1054-1062.

27. Teramoto S, Fukuchi Y, Nagase T, Matsuse T, Orimo $\mathrm{H}$. A comparison of ventilation components during exercise between elderly and young men. J Gerontol (Biol Sci) 1995; 50: B34-B39.

28. Wright RR. Elastic tissue of normal and emphysematous lung: a tridimensional histologic study. Am J Pathol 1961; 39: 355-367.

29. Kondo T, Tagami S, Yoshioka A, Nishimura M, Kawakami Y. Current smoking of elderly men reduces antioxidants in alveolar macrophages. Am J Respir Crit Care Med 1994; 149: 178-182.

30. Cantin AM, Begin R. Glutathione and inflammatory disorders of the lung. Lung 1991; 169: 123-138.

31. Borok Z, Buhl R, Grimes GJ, et al. Effect on glutathione aerosol on oxidant-antioxidant imbalance in idiopathic pulmonary fibrosis. Lancet 1991; 338: 215-216.

32. Pacht ER, Timerman AP, Lykens MG, Merola AJ. Deficiency of alveolar fluid glutathione in patients with sepsis and the adult respiratory distress syndrome. Chest 1991; 100: 1397-1403.

33. Harman D. Aging: a theory based on free radical and radiation chemistry. J Gerontol 1956; 11: 298-300.

34. Sohal RS, Allen RG. Oxidative stress as a causal factor in differentiation and aging: a unifying hypothesis. Exp Gerontol 1990; 25: 499-522.

35. Uejima Y, Fukuchi Y, Nagase T, et al. Influences of inhaled tobacco smoke on senescence accelerated mouse (SAM). Eur Respir J 1990; 3: 1029-1036.

36. Uejima Y, Fukuchi Y, Nagase T, Tabata R, Orimo H. A new murine model of aging lung: the senescence accelerated mouse (SAM)-P. Mech Ageing Dev 1991; 61: 223-236.

37. Cantin AM, North SL, Hubbard RC, Crystal RG. Normal alveolar epithelial lining fluid containing high level of glutathione. J Appl Physiol 1987; 226: 1401-1407. 